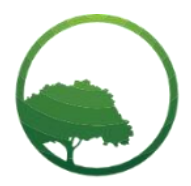

Research in Business \& Social Science

IJRBS VOL 10 NO 8 ISSN: 2147-4478

\title{
The moderating effect of gender on the contribution of social enterprises to social transformation in Kiambu County, Kenya
}

\author{
(D) Francis Kigo Njenga ${ }^{(a)}$ (DD Daniel M Kitonga ${ }^{(b) *}$ (D) Francis M. Gatumo ${ }^{(c)}$ \\ ${ }^{(a, b)}$ Tangaza University College, Catholic University of Eastern Africa, Kanya \\ (c) United States International University- Africa, Nairobi, Kenya
}

A R T I C L E I N F O
Article history:
Received 27 October 2021
Received in rev. form 17 Dec.
Accepted 22 December 2021
Keywords:
Enterpreneurs Gender, Social
Enterprise Activities, Social
transformation.
JEL Classification:
I3, G5, M38

\section{A R T ICLE INFO}

I3, G5, M38

\begin{abstract}
A B S T R A C T
This study sought to establish the moderating effect of social entrepreneurs' gender on the contribution of social enterprises to social transformation in Kiambu County, Kenya. The study used a descriptive survey design guided by mixed methods research on 322 sampled social enterprises drawn from a target population of 1944 social enterprises distributed across the 12 sub-counties of Kiambu County. Data were collected using survey questionnaires and interview guide instruments. A simple random sampling technique was used to get the proportionate sample for each stratum. In data analysis, both descriptive statistics (mean, percentages, standard deviation and frequencies) and inferential statistics (correlation and regression analysis) were applied. The findings showed the influence of the independent variable on the dependent variable being explained by $R$ of 0.568 . The findings also revealed that social entrepreneurs' gender was likely to have an effect on the relationship between social entrepreneurship and social transformation of $R 2=0.322$. By the estimates of the F-test, social entrepreneurship was found to predict social transformation by $F(3,281)=77.330, p<.05$.
\end{abstract}

(C) 2021 by the authors. Licensee SSBFNET, Istanbul, Turkey. This article is an open access article distributed under the terms and conditions of the Creative Commons Attribution (CC BY) license (http://creativecommons.org/licenses/by/4.0/)

\section{Introduction}

In recent years, researchers have become increasingly interested in studying social entrepreneurship. A number of scholars have suggested that social entrepreneurship and social enterprises contribute immensely to societal development. For instance, the period between 2002 and 2017 observed a growing acknowledgment of the popularity of social entrepreneurship and social enterprises on a local, national and international level, in comparison to previous decades where the concepts were less discussed (Defourny \& Nyssens, 2012, p. 1).

The Secretariat on Economic and Social Commission for Asia and the Pacific, (2017), acknowledged that to support the 2030 Agenda for Sustainable Development different enterprises and institutions will need to embrace social impact objectives in their business models. According to the views of some scholars, poverty is one of the most pressing social problems of the 21st century (Dacanay, 2013; Bruton \& Ketchen, 2013).

Accordingly, Linna, (2011, p. 10), claimed that at the bottom of the pyramid (BOP), cooperatives and other institutions or organisations are popular in addressing social needs. These arguments attest to the fact that social entrepreneurs are agents of social change whose target is the social sector. This characterization is congruent with purpose of this study to investigate the influence of social enterprises on social transformation in Kiambu County.

* Corresponding author. ORCID ID: 0000-0001-8202-8944

(C) 2021 by the authors. Hosting by SSBFNET. Peer review under responsibility of Center for Strategic Studies in Business and Finance.

https://doi.org/10.20525/ijrbs.v10i8.1425 
According to Borzaga and Galera, (2012), by the end of the 1970s in Italy the welfare system showed limitations and weaknesses in addressing, unemployment growing numbers of old people, homelessness, drug addiction and immigration. These limitations saw the growth of social entrepreneurship in Italy, as was the case in other countries. In regards to the role of social enterprises, Madill, et al., (2010), argues that, "social enterprises are established to address social needs and alleviate social problems, thereby seeking to attain social transformation (p. 137)". Bertolini, (2019), argues that despite diverse interventions on social problems, rural poverty, and other problems are still an irritation to many in developing countries.

In this study, it is aimed to examine the moderating effect of social entrepreneurs' gender on the contribution of social enterprises to social transformation in Kiambu County, Kenya. In our analysis, a descriptive survey design has been used and guided by mixed methods research on 322 sampled social enterprises drawn from a target population of 1944 social enterprises distributed across the 12 sub-counties of Kiambu County. Simple random sampling technique has been employed to get the proportionate sample for each stratum.

Following the literature review part with theoretical and empirical review sections, data and method has been introduced under research methodology part. Finally, this paper concludes with findings, discussion and conclusions.

\section{Literature Review}

\section{Theoretical and Conceptual Background}

\section{Social entrepreneurship and social transformation}

Bill Drayton, the founder of Ashoka foundation comments that, "social entrepreneurs are not contended to give a fish but to teach how to fish". According to the Ashoka foundation, "social entrepreneurs will not rest until they have transformed the fishing industry." The foundation observed that, social entrepreneurs are transformers who create large-scale transformations through pattern-breaking ideas, address the root causes of social problems, possess the ambition to create systemic transformation and persuade others to adopt it and transform the social systems. These transformations bring about good life for all but mostly for the marginalized in the society both locally and globally. Zahra and Wright (2016) developed, five pillars on the social role of entrepreneurship impact, namely, entrepreneurial activities and improving the quality of life, achieving progress, and enriching human existence; identifying ways to reduce dysfunctional effects of entrepreneurial activities on stakeholders; redefining the scope of entrepreneurial activities; recognizing entrepreneurship's social multiplier; and pursuing blended value. These pillars provide a crucial pathway to economic, technological, and social growth and development.

Accordingly, Zahra and Wright observed that, "entrepreneurs are catalysts of transformation thus understanding of the value of entrepreneurship increases its potential social role becomes more evident (p. 29)". As can be seen from the views social entrepreneurs have to embrace the call to solve social problems despite their gender orientations.

Social transformation is the process of change in institutionalized relationships, norms, values, and hierarchies over time. It is how society changes due to economic growth, science, technological innovations, war or political upheavals. Social transformation influences people's interactions and lifestyle. However social transformation does not end with the transformation of structures. It also concerns individual transformation which refers to the process of altering the social status of one's parents to resemble their status. During this process of transformation, one moves from an ascribed status to an achieved status. According to Bansal, Garg, and Sharma (2019) in a study on, "Social Entrepreneurship as a Path for Social Change and Driver of Sustainable Development: A Systematic Review and Research Agenda" social entrepreneurship is acknowledged, "as a tool to attain sustainable development". Bansa, et al., observed that, "social entrepreneurship triggers social change for sustainable development".

Bansal, et al., "reviewed 173 research papers from the Web of Science database" and established that, "sustainable development aimed at resolving poverty, inequality, and safety among other social issues in developing countries". Bansal et al., concluded that, "social entrepreneurs need to increase their focus in the developing world". Bansal et al. recommends a research be conducted to establish the picture of social entrepreneurship. This recommendation gives justification for the current study in Kiambu County.

Social entrepreneurship promises that individuals, can create novel business ideas to address society's most pressing problems, such as poor access to food, clean water, healthcare, and education (Yunus, 2010). Social enterprises have, a dual identity, also referred to as hybridity (Nicholls, 2010). Similarly, according to Praszkier and Nowak, (2011), in order to generate transformation, social entrepreneurs must have an entrepreneurship spirit which lead to social mission in order to create and sustain social value. Lumpkin, et al., (2013) upholds this view that, "taking care of relentless social issues necessitate that a social undertaking move into the obscure and increment its risk-taking capacity".

According to Lumpkin, et al., "communities and societies are ever evolving either positively or negatively". Lumpkin, et al., noted that, "this evolution brings about the desired or undesired benefits to the community/ society". It is important to establish the kind of transformation brought about by the presence of social enterprises at least in rural areas, hence the focus of the current study in Kiambu County. 


\section{Empirical Review}

\section{Gender and social entrepreneurship/entrepreneurship}

Gender has been a state of conversation among business studies' researchers for a while now. There have been a few investigations completed, "on gender and various aspects of business venture". Important to the current study was, the connection between gender, social business and social change. A study by Henry, Foss, and Ahl (2016) on, "Gender and entrepreneurship research: A review of methodological approaches" observed that, "early analyses of women's entrepreneurship have moved away from a 'gender as a variable' (GAV) approach (Cromie, 1987) towards those adopting a focus on 'gender as an influence' (Marlow, 2002)”. Further, Henry, Foss, and Ahl (2016) noted that, "while, early studies equated gender with sex, post-structuralist studies use a more apposite definition of the word gender, namely, social practices and representations associated with femininity or masculinity". While all these discussions are on-going, there has been a firm observation that literature has continued to report studies that merely compare men and women, with practically no consideration to developments in gender debate.

However, Teasdale, McKay, Phillimore, and Teasdale (2011) observed that, "to better understand how gender is performed within the field of social entrepreneurship, it is important to compare men and women's representation within social enterprises and third sector organisations (p. 63)". Teasdale et al, noted that, "there were no generalisable studies exploring gender within private sector social enterprises, there is a limited literature pertaining to gender and the third sector, and a far wider literature on gender and private sector work organisations (p. 63)". According to Teasdale, et al, "women's low rates of participation as conventional entrepreneurs and as leaders of private sector social enterprises was partially explained by their being pulled (attracted) or pushed (compelled) to undertake entrepreneurial activity in less profit-orientated settings (p. 69)". The arguments of Teasdale et al, provide a solid basis for studies of the effect of gender as contemplated in the current study. This is evident in Teasdale et al, who held that, "within the third sector, women initiating social ventures are almost as prevalent as men, and that around $40 \%$ of those leading social ventures are women (p. 69)".

More so, Zeffane (2014) in a study on, "gender, trust and risk-taking showed that gender differences tend to affect intentions to become an entrepreneur". Zeffane established that, "the issue of gender and its effect on entrepreneurship has been a subject of much debate and controversies (p. 221)". Zeffane observed that, "while, some studies showed that gender differences tend to affect intentions to become an entrepreneur, other studies deny any significant differences in this regard (p. 221)".

Gherardi and Poggio (2018, p.1) in a book on, "gender and entrepreneurship as an intertwined social practice: Evidence from Italy" noted that, "although the literature on women entrepreneurship has grown rapidly since 1990, its focus on individual women and their businesses does not explain current patterns of women's entrepreneurship". This conclusion was because "the basic assumptions posited by scholars showed women as inadequate and incomplete entrepreneurs, while there was scant empirical evidence of such underperformance (Marlow \& McAdam, 2013)". Interestingly, the discussion on this issue is not the mandate of the current study. However, by trying to understand the moderating effect of gender on social enterprises' activities and social transformation will shed light on the role that gender plays without discriminating issues of sex.

A study by Palalic, Ramadani and Dana (2017) on, "entrepreneurship in Bosnia and Hazergovina, with focus on gender it was revealed that there were significant differences in entrepreneurial performance between women and men". Palalic et al., (2017) found that, "gender significantly affects entrepreneurial activities in firms concerning innovativeness, proactiveness and risk-taking. Overall, female respondents scored better in entrepreneurial dimensions than did males". However, from the study it is not clear how gender affects the social entrepreneurship, which has a different focus than traditional entrepreneurship and social transformation.

A study by Pines, Lerner, and Schwartz (2010) reviewed literature, "on gender differences in entrepreneurship, focusing on the period between 2007 and 2008 Global Entrepreneurship Monitor (GEM) studies that examined the rates of entrepreneurship in 43 countries". The study revealed that, "the rates of women entrepreneurs was lower than men". Sánchez (2012) carried out a study on, "gender differences and attitudes in entrepreneurial intentions: the role of career choice". The study focused on, "gender differences in entrepreneurial intentions and agentic traits linked to locus of control, entrepreneurial self-efficacy, risk-taking propensity, and proactiveness using a sample of Spanish University students, 535 women and 283 men”. Sánchez (2012, p. 9) explains that, "gender differences in occupational interests and status, has occupied the interests of scholars where the bottom line has been that being a man or a woman does not directly affect career motivation, career choice, or career commitment". According to the study by Sánchez (2012, p. 16), the "effect of gender was significant and the differences in entrepreneurial intentions and traits between men and women, $F(5,700)=2.81, p<.05, \mathrm{\eta} 2=.98$ ".

Sarfaraz, Faghih, and Majd (2014, p. 1) did a study on, "the relationship between women entrepreneurship and gender equality". Sarfaraz, "used empirical data obtained from Global Entrepreneurship Monitor (GEM) on Women Adult Population Surveys 2007 and the United Nations 2007/2008 Development Index". Sarfaraz observed that, "the GEM data set for 2007 included 41 countries across the globe and that from 145,248 interviewees in the GEM 2007 APS, 49.9\% were women (p. 4)". Sarfaraz, et al., noted that, "the degree to which entrepreneurship affects the economy depends on numerous factors, including quality, gender composition, and type of entrepreneurial activity". From the GEM report, "gender and entrepreneurship are key factors in economic development". In fact, Sarfaraz, et al., (2014) observed that, "entrepreneurship gives women the flexibility to handle their domestic responsibilities by providing financial support for their family". 
This is argument is supported by the fact that "women entrepreneurship has been known as an important unexploited source of economic growth in the last decade (Georgeta, 2012)". Although the focus of Georgeta was on women, the current study sought to understand the role of gender plays in general in social entrepreneurship and social transformation. The studies by Sarfaraz et al, and Georgeta were informative to the current study.

Quaye, Acheampong, and Asiedu (2015, p. 128) explored, "the differences in entrepreneurial orientation between men and women using data from a survey of 300 small and medium-scale (SMEs) enterprises from Accra, Ghana". The findings indicate that, "there were significant differences between the levels of entrepreneurial orientation among the genders". These differences are in "risktaking, innovativeness and proactiveness". Men were more "entrepreneurially oriented than women were". Ouaye et al., (2015) attributed the differences in their findings, "to the different socio-economic conditions that men and women are exposed to". While Ouaye, et al., (2015) established very interesting findings, but failed to explicitly situate gender as a moderator in the relationship between social enterprises' activities and social transformation.

Kikooma (2012) in an examination on, "gender and entrepreneurship in Uganda, observed that clarifications of entrepreneurial experiences remain to a great extent rooted in unorthodoxy zeroed in on correlations of male and female entrepreneurs (p. 15)". Further, Kikooma (2012, p. 27) reasons that, "the utilization of gender and cultural interfaces as conceptual tools with which to examine entrepreneurship, as both an economic phenomenon, can be seen as a first step towards rethinking female entrepreneurship discourse".

Mungai and Ogot (2012, p. 175) in a study on, "gender, culture and entrepreneurship in Kenya" observed that, "greater part of studies had been done in Western and in developed societies where national cultures have evolved and dominated the literature on the 'cultural perspective' on gender and entrepreneurship". Mungai and Ogot (2012), nonetheless observed that, "in most of sub-Saharan nations, ethnic societies played a significant role in moulding the values and perceptions of citizens than national cultures". Mungai and Ogot (2012) inferred that, "the differential rate of gender involvement was compared among four Kenyan ethnic groups namely Luo, Kikuyu, Kalenjin and Kamba”.

Okello (2020) did a study on, "gender effect of entrepreneurial orientation on dairy farming career resilience in Kenya". The study examined, "the moderating role of gender on the relationship between future orientation, market orientation, risk-taking orientation, and social orientation and entrepreneurial resilience". Okello, "surveyed 682 respondents comprising of 480 males and 202 female dairy agripreneurs in Murang'a County, Kenya using a cross-sectional study design". Okello (2020) established that, "gender moderates the entrepreneurial orientation-agripreneurial career resilience relationship whereby female agripreneurs had statistically significant higher risk-taking propensity of $(\beta=0.189, p=0.06)$ compared to their male counterparts $(\beta=0.054, p=0.06)$ ".

\section{Research and Methodology}

\section{Data}

The study used a descriptive survey for a sample size of 322 social enterprises sampled from a target population of 1944 in Kiambu County. The sampling technique used on probability was stratified sampling and on non-probability purposive sampling. The data collection instrument was a self-designed questionnaire.

\section{Questionary}

The questionnaire comprised of a variety of questions flowing from the study variables. The questionnaires were self-administered, delivered and collected by trained research assistants. Quantitative data was examined through descriptive statistics and inferential statistics. Before administering the data collection instrument, a pilot study was conducted in Nairobi County. This was done to enable the researchers to detect and correct any weakness in the instruments. Kothari (2008); Sekaran (2013) and Cooper and Schindler (2011), suggests that, $1 \%$ of the sample should constitute the pilot test for a pilot study. In this study, $1 \%$ sample size was adopted for the pilot study.

\section{Reliability}

Internal consistency reliability was applied to quantify various aspects of social enterprises. Cronbach's coefficient alpha was used to gauge internal consistency reliability among the items of the current study. As indicated by Mugenda and Mugenda (2009), instruments are dependable if the unwavering quality coefficient is above 0.7 . The suggested value of 0.7 was utilized as a cut-off of unwavering quality. Two considerations were used in ensuring content validity. First, content validity was ensured through an exhaustive literature review. Secondly, academic discussions were held with experts for purposes of content validation during the formulation of the instrument. This ensured the instrument captured important questions regarding the variables.

\section{Analysis and Findings}

\section{Response Rate Results}

The response rate is the level of individuals who responded to a study. According to Orodho (2003), "the response rate is the degree to which the final data sets incorporate all sampled individuals and is determined as the number of respondents with whom interviews 
are completed and divided by the absolute number of respondents of the whole sample including none respondents". This study sampled 322 social enterprises. The researcher distributed 322 questionnaires. The response and non-response rate is presented in Table 1 .

Table 1: Response Rate

\begin{tabular}{lll}
\hline Questionnaire & Frequency & Percentage \\
\hline Returned & 285 & $88.5 \%$ \\
Not Returned & 27 & $11.5 \%$ \\
Total & 322 & $100 \%$
\end{tabular}

According to the results in Table 4.1, from the 322 questionnaires distributed, 285 questionnaires were considered to be properly filled (these were collected by the researcher from the field). From the returned questionnaires, it is conclusive that the overall response rate is determined to be $88.5 \%$ against a non-response rate of $11.5 \%$.

Therefore, from the findings in Table 4.1, "the non-response rate of $11.5 \%$ was insignificant as it would not affect the analysis of the findings". Kothari (2014) observed that, "a response rate of 50\% is normal while a response rate between $60-70 \%$ is satisfactory", which supports this conclusion. Kothari (2014) further adds that, "a response rate that is above $70 \%$, is excellent". The researcher tried to achieve an acceptable response rate by ensuring the data collection instruments were coherent, clear and concise. Further, the researcher sought written consent from the participants and was ever available throughout the researcher process to clarify any concern from the respondents. By ensuring these aspects were incorporated in the study design, the researcher was able to achieve a response rate above $70 \%$.

\section{Respondents Gender Distribution}

The study sought to identify the gender distribution of the participants of the study.

Table 2: Gender Distribution

\begin{tabular}{llll}
\hline Gender & & Frequency & Percent \\
\hline \multirow{2}{*}{ Valid } & Male & 128 & 44.9 \\
& Female & 157 & 55.1 \\
& Total & 285 & 100.0 \\
\hline
\end{tabular}

From the gender results as tabulated in Table 1, the participants in this study included male and female. The participation in regards to gender as depicted in Table 1 shows that $55.1 \%$ (157) were females while $44.9 \%$ (128) were males. From the results in Table 2 , we conclude that the participants were from either gender and the study is representative of either gender.

\section{Study hypothesis}

The moderating effect of gender on the relationship between social enterprises' activities and social transformation in the study was guided by the following hypothesis:

Ho1: Gender does not have moderating effect on the relationship between social enterprises' activities and social transformation by social enterprises in Kiambu County

Ha: Gender has significant effect on the relationship between social enterprise' activities and social transformation in Kiambu County, Kenya.

The hypothesis of the study was that there is no significant moderating effect of gender on the relationship between social enterprises' activities and social transformation by social enterprises in Kiambu County. Directed regression investigation was done to test the impact of gender orientation on the relationship between social enterprises' activities and social transformation in Kiambu County. Regression examination was directed for all independent factors with the moderating variable and dependent variable. The balance impact of gender on all social business venture activities and social transformation by social enterprises in Kiambu County was tested utilizing the hierarchical Moderated Multiple Regression (MMR) model (Baron \& Kenny, 1986).

$$
Y=B_{O}+61 X 1 * Z+62 X 2 * Z+63 X 3 * Z+64 X 4 * Z+e
$$

Where,

$Y=$ Social Transformation by Social Enterprises

$X 1=$ Entrepreneurial Orientation

$X 2=$ Entrepreneurial Capital 
$X 3=$ Entrepreneurial Culture

$Z=$ Gender (moderating variable)

$e=$ Standard error term.

The SPSS was utilized to demonstrate the values of $\beta 1, \beta 2, \beta 3$, and $\beta 4$ and the outcomes are introduced in Table 4.67. The condition for dismissing the null hypothesis was the result of the p-value set at under 0.05 . The extent of the moderating impact is displayed by the adjustment of $R^{2}$ in the model synopsis. In Table 4.67, Model 1 presents the various regression results for social enterprises' activities and social transformation by social enterprises undertakings without moderator variable. Model 2 presents the hierarchical Moderated Multiple Regression results for social enterprises' activities and social transformation by social enterprises with the moderating variable.

Table 3: Model Summary

\begin{tabular}{llllll}
\hline Model & R & R Square & Adjusted R Square & $\begin{array}{l}\text { Std. Error } \\
\text { Estimate }\end{array}$ & of theDurbin-Watson \\
\hline 1 & $.633^{\mathrm{a}}$ & .401 & .393 & 9.68138 & \\
2 & $.878^{\mathrm{b}}$ & .771 & .765 & 6.02329 & 1.731 \\
\hline
\end{tabular}

a. Predictors: (Constant), $X 4, X 2, X 1, X 3$

b. Predictors: (Constant), X4, X2, X1, X3, X4*Z, X2*Z, X3*Z, X1*Z

c. Dependent Variable: $S T$

From Table 3, model 1 shows the coefficient of determination ( $R$ squared) is 0.401 . This is a pointer that $40.1 \%$ of social enterprises variety is, clarified by the independent factors without the moderator. In like manner, in model 2 , the changed $R$-squared of 0.765 demonstrates that with the presentation of the moderator, the model can clarify the variance in social transformation by social enterprises by $76.5 \%$. The $R$ - value of 0.633 shows that a positive relationship exists between the factors registered under Table 3 . The standard error of estimation is 9.68138 and 6.02329 which shows the normal deviation of the independent factors from the line of best fit.

After introduction of the moderating variable, the findings from in model 2 indicated a change in R-square from 0.401 to 0.771 . This indicates that gender enhanced the relationship between social enterprises' activities and social transformation by social enterprises. This is an indicator that the model became significant when the moderator was, introduced since there was change in $R$-square.

fter introduction of the moderating variable, the findings in model 2 demonstrate an adjustment of $R$-square from 0.401 to 0.771 . This demonstrates that gender improved the connection between social enterprises' activities and social transformation by social enterprises. This is a marker that the model became significant when the moderator was introduced. From these outcomes, gender is concluded to have a significant impact on social enterprises' activities and social transformation by social enterprises in Kiambu County, Kenya.

Table 4: ANOVA Test

\begin{tabular}{lllllll}
\hline Model & & Sum of Squares & df & Mean Square & F & Sig. \\
\hline \multirow{2}{*}{1} & Regression & 20231.389 & 4 & 5057.847 & 53.962 & $.000^{\mathrm{b}}$ \\
& Residual & 30274.523 & 323 & 93.729 & & \\
& Total & 50505.912 & 327 & & & $.000^{\mathrm{c}}$ \\
\multirow{2}{*}{2} & Regression & 38932.589 & 8 & 4866.574 & 134.139 & \\
& Residual & 11573.322 & 319 & 36.280 & & \\
& Total & 50505.912 & 327 & & & \\
\hline
\end{tabular}

\footnotetext{
a. Dependent Variable: ST

b. Predictors: (Constant), X4, X2, X1, X3

c. Predictors: (Constant), X4, X2, X1, X3, X4*Z, X2*Z, X3*Z, X1*Z
}

Table 4 indicates that the overall regression model between social transformation by social enterprises and social enterprises' activities with the moderating variable $(X 4=$ Gender, $X 3=$ Entrepreneurial Culture, $X 2=$ Entrepreneurial Capital, $X 1=$ Entrepreneurial Orientation) is significant at $F$-statistics of 53.962 and 134.139 respectively. This is inferred from the results of the $F$-statistic values which are greater than the critical value of 2.38 and the $p$-value of 0.000 below 0.05 . 
Table 5: Beta Coefficients

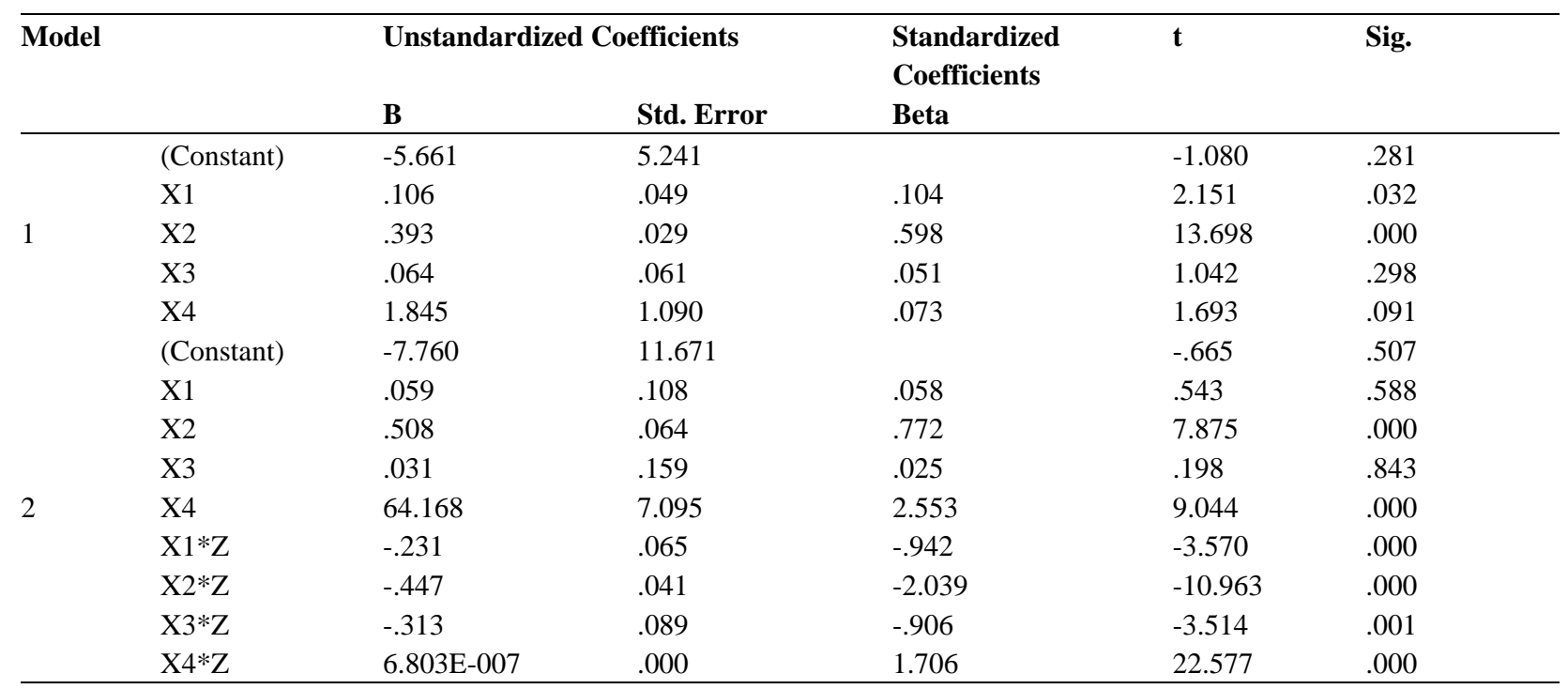

a. Dependent Variable: ST

As per the beta coefficients in Table 5, there is a huge distinction in the beta coefficients prior and after the introduction of the moderating variable. This is upheld by scrutinizing the p-values results which are below 0.05 . The overall regression model with gender is characterized as:

$Y=-7.760-.942 X_{1} * Z-2.039 X_{2} * Z-.906 X_{3} * Z+1.706 X_{4} * Z$

Where $X_{4}=$ Gender, $X_{3}=$ Entrepreneurial Culture, $X_{2}=$ Entrepreneurial Capital, $X_{1}=$ Entrepreneurial Orientation and $\mathrm{Z}=$ Gender. This model was contrasted with the model without the moderating variable $\left(Y=-5.661+104 X_{1}+.598 X_{2}+.051 X_{3}+.073 X_{4}\right)$ where a huge change in beta coefficients was noted. This suggests that with the introduction of gender there is an impact of the social enterprises' activities on social transformation by social enterprises in Kiambu County. As per the Moderated Multiple Regression results, the study discovered that gender had a moderating effect on the relationship between social entrepreneurs' activities and social transformation by social enterprises in Kiambu County.

\section{Conclusion}

Significant studies have been performed on gender and entrepreneurship but there were no established studies on gender as a moderator to the influence of social enterprises' activities and social transformation. The study sought to examine the moderating effect of gender on social enterprises' activities and social transformation by social enterprises. From the results of the assumed model, it is evident that by examining the changed $R$-squared after the introduction of the moderator, the model can clarify the variance in social transformation by social enterprises by $76.5 \%$. Likewise, the $R$-value of 0.633 shows that a positive relationship exists between the variables of the study. Further, the results of the overall regression model between social transformation by social enterprises and social enterprises' activities with the moderating variable it is evidenced by significant $F$-statistics of 53.962 and 134.139 respectively. This is inferred from the results of the $F$-statistic values which are greater than the critical value of 2.38 and the $p$-value of 0.000 below 0.05 . From these results, gender is, concluded to have a significant moderation effect on social enterprises' activities and social transformation by social enterprises in Kiambu County, Kenya.

Author Contributions: Conceptualization, FKN, DMK, FMG;Methodology, FKN, DMK, FMG;Data Collection, FKN, DMK, FMG;Formal Analysis, FKN, DMK, FMG; Writing—Original Draft Preparation, FKN, DMK, FMG;Writing—Review And Editing, FKN, DMK, FMG; All authors have read and agreed to the published the final version of the manuscript.

Institutional Review Board Statement: Ethical review and approval were waived for this study, due to that the research does not deal with vulnerable groups or sensitive issues.

Data Availability Statement: The data presented in this study are available on request from the corresponding author. The data are not publicly available due to privacy.

Conflicts of Interest: The authors declare no conflict of interest.

\section{References}

Bansal, S., Garg, I., \& Sharma, G. D. (2019). Social entrepreneurship as a path for social change and driver of sustainable development: A systematic review and research agenda. Sustainability, 11(4), p. 1091.

Bencheva, N., Stoeva, T., Terziev, V., Tepavicharova, M., \& Arabska, E. (2017). The role of social entrepreneurship for rural development, Agricultural Sciences, 9(21), pp. 89-98. https://doi.org/10.22620/agrisci.2017.21.014 
Bertolini, P. (2019). Overview of income and non-income rural poverty in developed countries. Presentation. Retrieved, 5, 2020. https://www.un.org/development/desa/dspd/wp-content/uploads/sites/22/2019/03/bertolini-Overview-rural-povertydeveloped-countries-1.pdf

Borzaga, C., \& Galera, G. (2012). The concept and practice of social enterprise. Lessons from the Italian Experience. International Review of Social Research, 2(2), pp. 85-102.

Buckmaster, N. (1999). 'Associations between outcome measurement, accountability and learning for non-profit organizations', The International Journal of Public Sector Management, 12(2), pp. 186-197.

Cromie S (1987). Motivations of aspiring male and female entrepreneurs. Journal of Organizational Behavior 8(3), $251-261$.

Defourny, J., \& Nyssens, M. (2012). The EMES approach of social enterprise in a comparative perspective. In EMES conference selected papers. URL: http://dial.academielouvain.be/vital/access/services/ Download/boreal: 114773/PDF_01.

Georgeta, I. (2012). Women entrepreneurship in the current international business environment. Cogito-Multidisciplinary Research Journal, 1, 122-131.

Gherardi, S., \& Poggio, B. (2018). Beyond the gender-neutral approach: Gender and entrepreneurship as an intertwined social practice. In Contextual Embeddedness of Women's Entrepreneurship (pp. 272-284). Routledge.

Haugh, H. (2006). 'Social enterprise: beyond economic outcomes and individual returns', in Mair, J., Robinson, J. and Hockerts, K. (Eds), Social Entrepreneurship, Macmillan, New York, NY.

Henry, C., Foss, L., \& Ahl, H. (2016). Gender and entrepreneurship research: A review of methodological approaches. International Small Business Journal, 34(3), 217-241.

Jilenga Moga(2017), Social Enterprise and Economic Growth: A Theoretical Approach and Policy Recommendations International Journal of Academic Research in Accounting Finance and Management Sciences 7(1) https://doi.org/:10.6007/IJARAFMS/v7-i1/2538

Kikooma, J. (2012). Gender and entrepreneurship in Uganda: Women manoeuvring economic space. In Entrepreneurship-Gender, Geographies and Social Context. IntechOpen.

Kosa, A., Mohammad, I., \& Ajibie, D. (2018). Entrepreneurial orientation and venture performance in Ethiopia: the moderating role of business sector and enterprise location. Journal of Global Entrepreneurship Research, 8(1), pp. 1-17.

Linna, P. (2011). Community-level entrepreneurial activities: Case study from rural Kenya. International Journal of Business and Public Management, 14.

Lumpkin, G. T., Moss, T. W., Gras, D. M., Kato, S., \& Amezcua, A. S. (2013). Entrepreneurial processes in social contexts: how are they different, if at all? Small Business Economics, 40(3), 761-783.

Madill, J., Brouard, F., \& Hebb, T. (2010). Canadian social enterprises: An empirical exploration of social transformation, financial self-sufficiency, and innovation. Journal of Nonprofit and Public Sector Marketing, 22(2), pp. 135-151.

Mair, J., \& Noboa, E. (2006). Social entrepreneurship: how intentions to create a social venture are formed?, In Mair, J., Robinson, J. and Hockerts, K. (Eds), Social Entrepreneurship, Macmillan: New York.

Malunga, P., Iwu, C. G., \& Mugobo, V. V. (2014). Social Entrepreneurs and Community Development. A Literature Analysis, Mediterranean Journal of Social Sciences, 5(16), pp. 18-26.

Marlow, S. (2002). Self-employed women: A part of or apart from feminist theory? International Journal of Entrepreneurship and Innovation, 2(2), 83-91.

Martin, R., \& Osberg, S. (2007). Social entrepreneurship: the case for definition, Stanford Social Innovation Review, available at: www.skollfoundation.org/media/skoll_docs/2007SP_feature_martinosberg.pdf.

Mungai, E. N., \& Ogot, M. (2012). Gender, culture and entrepreneurship in Kenya, International Business Research, 5(5), $175-183$.

Nicholls, A. (2010). The legitimacy of social entrepreneurship: Reflexive isomorphism in a pre-paradigmatic field. Entrepreneurship theory and practice, 34(4), pp. 611-633.

Okello, D. (2020). Gender effect of entrepreneurial orientation on dairy farming career resilience in Kenya. Cogent Food \& Agriculture, 6(1), 1863565, https://doi.org/10.1080/23311932.2020.1863565

Palalic, R., Ramadani, V., \& Dana, L. P. (2017). Entrepreneurship in Bosnia and Herzegovina: focus on gender. European Business Review.

Pines, A.M., Lerner, M. \& Schwartz, D. (2010). Gender differences in entrepreneurship, Equality, Diversity and Inclusion: An International Journal, 29(2), pp. 186-198.

Praszkier, R., \& Nowak, A. (2011). Social entrepreneurship: Theory and practice. Cambridge University Press.

Quaye, D., Acheampong, G., \& Asiedu, M. (2015). Gender differences in entrepreneurial orientation: Evidence from Ghana. European Journal of Business and Management, 7(12), 128-140.

Sarfaraz et al. (2014). The relationship between women entrepreneurship and gender equality. Journal of Global Entrepreneurship Research, 2(6), https://doi.org/10.1186/2251-7316-2-6

Teasdale, S., McKay, S., Phillimore, J., \& Teasdale, N. (2011). Exploring gender and social entrepreneurship: women's leadership, employment and participation in the third sector and social enterprises. Voluntary sector review, 2(1), 57-76.

Vickers, I. (2010). Social enterprise and the environment: a review of the literature. Third Sector Research Centre Working Paper, 22.

Young, R. (2006). For what it is worth: social value and the future of social entrepreneurship, In Nicholls, A. (Ed.), Social Entrepreneurship: New Models of Sustainable Social Change, Oxford University Press, New York, NY. 
Yunus, M. (2010). Building Social Business - The New Kind of Capitalism That Serves Humanity's Most Pressing Needs. Public Affairs, New York.

Zahra, S. A., \& Wright, M. (2016). Understanding the social role of entrepreneurship. Journal of Management Studies, 53(4), 610629.

Zappalà, G., \& Lyons, M. (2009). Recent approaches to measuring social impact in the Third sector: An overview. The Center for Social Impact, CSI background paper no. 5

Publisher's Note: SSBFNET stays neutral with regard to jurisdictional claims in published maps and institutional affiliations.

\section{(c) (1)}

(C) 2021 by the authors. Licensee SSBFNET, Istanbul, Turkey. This article is an open access article distributed under the terms and conditions of the Creative Commons Attribution (CC BY) license (http://creativecommons.org/licenses/by/4.0/).

International Journal of Research in Business and Social Science (2147-4478) by SSBFNET is licensed under a Creative Commons Attribution 4.0 International License. 